\title{
La importancia del informe de auditoría para el otorgamiento de crédito*
}

\author{
The importance of the audit report for credit granting \\ A importância do relatório de auditoria para a concessão de crédito
}

Boris Duckardt ${ }^{\text {a }}$

Universidad Nacional del Sur, Argentina

boris.duckardt@uns.edu.ar

ORCID: http://orcid.org/0000-0002-2680-8695

María de los Ángeles López

Universidad Nacional del Sur, Argentina

ORCID: http://orcid.org/0000-0001-7113-5939

Diana Albanese

Universidad Nacional del Sur, Argentina

ORCID: http://orcid.org//0000-0002-9462-5356

\section{Anahi Briozzo}

Universidad Nacional del Sur, Argentina

ORCID: http://orcid.org/0000-0002-7865-2821
DOI: https://doi.org/10.11144/Javeriana.cc20-50.iiao

Fecha de recepción: 02 Noviembre 2018

Fecha de aprobación: 24 Julio 2019

Fecha de publicación: 30 Noviembre 2019

\section{Resumen:}

El objetivo del presente artículo consiste en indagar sobre la relevancia de los informes de auditoría para los analistas de crédito de instituciones financieras y crédito comercial, como fuente de información para otorgar financiamiento. Se realizó un estudio de casos múltiples, recolectando los datos mediante entrevistas a analistas de crédito de instituciones bancarias, financieras y empresas comerciales de la ciudad de Bahía Blanca, provincia de Buenos Aires, Argentina. Los entrevistados consideran que la presentación de estados financieros auditados es fundamental para la calificación crediticia. En cuanto al informe de auditoría pareciera brindar confiabilidad, aunque las opiniones calificadas y la utilización de un párrafo de énfasis resultan ser una alerta para los analistas. Sin embargo, mencionaron que en general los informes presentan opiniones sin modificar. Los contadores y personas de altos cargos valoran más los informes de auditoría que los analistas de crédito que poseen otra formación y aquellos que ocupan cargos operativos, posiblemente por menor comprensión de su contenido.

Código JEL: M42

Palabras clave: Informe de auditoría, confiabilidad de la información, usuarios externos, financiamiento.

\section{Abstract:}

The aim of this paper is to examine the relevance of audit reports for credit analysts of financial institutions and commercial credit providers, as a source of information to grant financing. A multiple case study was conducted, collecting data through interviews with credit analysts from banking and financial institutions and commercial companies in the city of Bahia Blanca, province of Buenos Aires, Argentina. The interviewees consider that the presentation of audited financial statements is fundamental for credit rating. Regarding the audit report, it seems to provide reliability although qualified opinions and the use of an emphasis paragraph are an alert for analysts. However, they mentioned that, in general, the reports present unmodified opinions. Accountants and senior executives value audit reports more than credit analysts who have other training and those who hold operational positions, possibly due to less understanding of their content.

JEL Code: M42.

Keywords: Audit report, reliability of information, external users, financing.

\section{Resumo:}

O objetivo deste artigo é indagar sobre a relevância dos relatórios de auditoria para analistas de crédito de instituições financeiras e crédito comercial, como fonte de informação para concessão de financiamento. Um estudo de caso múltiplo

Notas de autor: 
foi realizado, e os dados foram coletados através de entrevistas com analistas de crédito de instituições bancárias, financeiras e empresas comerciais na cidade de Bahia Blanca, província de Buenos Aires, Argentina. Os entrevistados consideram que a apresentação de demonstraçõesfinanceiras auditadas é fundamental para a notação de risco. Em relação ao relatório de auditoria, parece fornecer confiabilidade, embora opiniões qualificadas e o uso de um parágrafo de ênfase sejam um alerta para os analistas. No entanto, eles mencionaram que, em geral, os relatórios apresentam opiniões não modificadas. Contadores e funcionários de alto cargo valorizam os relatórios de auditoria mais do que os analistas de crédito que têm outro treinamento e aqueles que ocupam cargos operacionais, possivelmente devido à menor compreensão de seu conteúdo.

Código JEL: M42.

Palavras-chave: Relatório de auditoria, fiabilidade da informação, utilizadores externos, financiamento.

\section{INTRODUCCIÓN}

La información contable es esencial para la toma de decisiones en los mercados financieros y de capitales. En particular, los proveedores de financiación requieren de sus clientes la presentación de estados financieros que reflejen la situación patrimonial de la empresa, el resultado de sus operaciones y el flujo de fondos durante un periodo determinado. Por su parte, los terceros usuarios no siempre cuentan con los conocimientos técnicos adecuados para leer e interpretar la información que contienen, ni para evaluar su calidad. Otro aspecto para tener en cuenta es que una de las características de las pequeñas empresas es la opacidad informativa, y en consecuencia la poca confianza que generan los estados financieros para los usuarios externos (Berger \& Udell, 2002

La opinión de un auditor independiente en su informe es relevante para dar seguridad razonable respecto a que los estados financieros no contienen errores o distorsiones significativas. La auditoría independiente es fundamental para otorgar credibilidad y confiabilidad a la información que contienen los estados fi nancieros que se sujetan a evaluación (Arens, Elder \& Beasley, 2007; FAFAE, 2014

En la Argentina, a diferencia de los países desarrollados y la mayoría de los países latinoamericanos, todas las empresas, incluso las PyMEs están obligadas a presentar estados financieros auditados. Por ende, se plantea la pregunta de investigación: ¿Los informes de auditoría que brindan opinión sobre la razonabilidad de los estados financieros, son relevantes para las entidades que otorgan financiamiento al momento de tomar sus decisiones?

El objetivo general del presente trabajo consiste en analizar la relevancia de los informes de auditoría como fuente de información para decidir otorgar financiamiento, desde la perspectiva de los analistas de crédito, tanto financieros como comerciales. A su vez, se plantean los siguientes objetivos específicos:

- Identificar la documentación considerada relevante para la calificación crediticia.

- Describir el nivel de comprensión por parte de los analistas de la información que brinda el informe de auditoría.

- Determinar la importancia que otorgan los analistas de crédito al informe de auditoría.

Se realizó un estudio de casos múltiples de tipo exploratorio-descriptivo, mediante entrevistas a 16 analistas de crédito de instituciones bancarias, financieras y empresas proveedoras de crédito comercial a clientes de la ciudad de Bahía Blanca, provincia de Buenos Aires, Argentina. Los resultados fueron analizados tanto cuantitativa como cualitativamente.

La originalidad de este trabajo radica en tres aspectos: primero, se estudia la relevancia del informe de auditoría en un contexto donde todas las sociedades están obligadas a presentar sus balances auditados; segundo, se analiza su importancia para el crédito comercial, además del financiero tradicionalmente estudiado; por último, se distinguen las respuestas en función de la formación universitaria de los encuestados, junto con su cargo profesional.

El trabajo se estructura del siguiente modo: en primer lugar, se expone el marco teórico sobre la importancia del informe de auditoría para la toma de decisiones por parte de los usuarios externos, en particular los 
analistas de crédito. Posteriormente se describe la metodología utilizada y a continuación, se exponen los resultados para finalmente presentar las conclusiones.

\section{REFERENCIAL TEÓRICO}

\section{La utilidad del informe de auditoría para el otorgamiento de crédito}

Mediante los estados financieros la dirección de una empresa brinda información sobre la situación patrimonial, los resultados y el flujo de fondos de un ente a usuarios con disímiles intereses y que deben tomar decisiones basados en los mencionados reportes. Según el International Accounting Standards Board (IASB, 2010 la información financiera debe ser útil para la toma de decisiones por parte de los principales usuarios: inversores, prestamistas y acreedores. La Resolución Técnica No 16 de la Federación Argentina de Consejos Profesionales en Ciencias Económicas -FACPCE- define a los acreedores, actuales y potenciales, entre los usuarios tipo de los estados contables.

El informe de auditoría consiste en la comunicación de los hallazgos sobre la razonabilidad de la información contenida en los estados financieros (Arens et al., 2007. La opinión de un auditor independiente agrega credibilidad respecto a que los estados financieros no contienen errores o irregularidades significativas, en la medida en que el profesional realice su tarea considerando los intereses de los usuarios que tomarán decisiones con base en ellos. De esta manera, el trabajo del profesional contribuye a que la información que brindan los estados financieros sea considerada menos riesgosa.

Por su parte, los analistas de crédito recurren a diferentes fuentes de información para tomar sus decisiones. La literatura sobre estructura de capital y financiamiento bancario indica que existen diversas variables que son consideradas por los proveedores externos de fondos al momento de definir el otorgamiento de un crédito y que pueden actuar como mejores predictores de la calidad crediticia de la empresa que los informes de auditoría.

Cassar (2011 señala que los analistas de créditos emplean información sólida adicional a los estados financieros, como historia de cumplimiento tributario, historial crediticio y calificaciones crediticias de terceros, considerándolos como aspectos que también reducen las asimetrías de información. Tienen en cuenta factores como el tipo de relación y la duración del vínculo con las instituciones bancarias, el tamaño, la antigüedad, la estructura de activos de la empresa y las características de los propietarios (Jensen \& Meckling, 1976; Jensen, 1986; Ang, 1991; Chittenden, Hall \& Hutchinson, 1996; Berger \& Udell, 2002; Briozzo \& Vigier 2009, 2014, 2016.

En lo que respecta al otorgamiento de crédito por parte de entidades bancarias, las normas generales son las establecidas por el Banco Central de la República Argentina. En la Comunicación A 6435 - Sección 1, denominada "Requisitos para el otorgamiento de financiaciones", se establece que por cada cliente -unidad económica receptora de fondos- el banco debe llevar un legajo, que debe contener todos los elementos que posibiliten efectuar la correcta identificación del deudor y las evaluaciones acerca de su patrimonio, flujo de ingresos y egresos, rentabilidad empresaria o del proyecto a financiar. En consecuencia, se deben presentar los estados financieros para cumplir con la información solicitada. Como excepción, la norma mencionada indica que cuando, de acuerdo con las normas sobre "Clasificación de deudores", no corresponda evaluar la capacidad de repago del deudor por encontrarse la deuda cubierta con garantías preferidas "A", no será obligatorio incorporar al legajo del cliente el flujo de fondos, los estados financieros o contables -según corresponda- ni información adicional para efectuar ese análisis.

Respecto de la utilidad del informe de auditoría en el proceso de calificación crediticia y otorgamiento de financiación, estudios precedentes muestran resultados contrapuestos. Por un lado, existe evidencia a favor de la utilidad del reporte de auditoría como mecanismo de reducción de los problemas de información. El 
riesgo de que la información utilizada para tomar la decisión de financiamiento sea incorrecta por la existencia de estados financieros inexactos se ve reducido si estos son acompañados de un informe de auditoría; así se incrementa la credibilidad de la información, pudiendo tener un efecto relevante en la capacidad del prestatario para obtener capital a un menor costo (Arens et al., 2007; Guiral \& Ruiz-Barbadillo, 2011).

Gyau, Owusu y Amaning (2016) consideraron el impacto que tiene sobre el monto del crédito a otorgar el hecho de que las organizaciones presenten o no estados financieros auditados, y encontraron que los analistas de crédito otorgan un monto mayor en el caso de entes que presentan información financiera auditada. Por su parte, Chen, He, Ma y Stice (2016) estudiaron la relevancia de las opiniones de auditoría en la contratación de deuda privada, y detectaron que los préstamos emitidos luego de una opinión calificada se asocian con mayores tasas de interés, cláusulas más restrictivas, préstamos de montos menores y con mayor probabilidad de exigencia de garantías.

Cha, Hwang y Yeo (2016) investigaron la relación entre la calificación crediticia y las opiniones de auditoría para un conjunto de empresas en inminente quiebra. Mediante un estudio empírico sobre 97 empresas de Corea detectaron que la auditoría tuvo una función predictiva de la quiebra inminente más acertada que la de los ratings de las agencias de calificación crediticia. Según argumentan, luego de una serie de fallas corporativas de alto perfil (como el caso Enron), los auditores se volvieron más conservadores que dichas agencias, siendo más creíbles y apropiados para los intereses del mercado financiero.

A su vez, la existencia de estados financieros auditados reduciría el problema de selección adversa y riesgo moral entre usuarios internos y externos (Jensen \& Meckling, 1976) y actuaría como una señal de la calidad de los mismos (Van Tendeloo \& Vanstraelen, 2008). Minnis (2011) analiza empresas de capital cerrado de los Estados Unidos y encuentra que aquellas que presentan balances auditados tienen menor costo de la deuda. Van Caneghem y Van Campenhout (2012) estudian la relación entre la cantidad y calidad de la información contable en PyMES belgas y su estructura de financiamiento. Encuentran que la probabilidad de contratar a un auditor externo (una medida de calidad) se relaciona positivamente con el endeudamiento.

Bacha (2014) estudió el efecto que tienen el buen gobierno corporativo y la calidad de la auditoría sobre el costo de la deuda en el financiamiento de empresas tunecinas. Los resultados indican que si la auditoría es realizada por una gran firma se garantiza la independencia del profesional auditor e incrementa la credibilidad de los acreedores en la información de la organización, lo cual impacta directamente reduciendo el costo de financiamiento.

Por último, es interesante mencionar que diversos estudios vinculan los grandes estudios de auditoría (conocidos como BigN, actualmente Big4: KPMG, Deloitte, Price Whaterhouse Cooper y Ernst \& Young) como una proxy de la calidad de la auditoría. Dado que la calidad de la auditoría depende de la competencia del auditor y de su independencia, se asume que empresas auditoras de mayor tamaño que tienen una mayor base de clientes cumplen mejor con estas condiciones (DeAngelo, 1981; Lai, 2009; Van Caneghem \& Campenhout, 2012).

Por otro lado, la opinión que brindan los contadores en sus informes ha sido cuestionada, al igual que la propia función de auditoría (Guiral, Ruiz \& Choi, 2014). Un estudio del caso chino realizado por Lin, Tang y Xiao (2003), concluye que los informes contienen información limitada para los usuarios, y que incluso estos no siempre los comprenden. Según su investigación, los informes calificados producen una baja de credibilidad en la información, pero principalmente en los oficiales de crédito, no así para las gerencias financieras. Los resultados revelan que los informes de auditoría no brindan gran información para la decisión de crédito -más allá de estar calificados o no-, lo que demostraría una necesidad de perfeccionar su formato y contenido para mejorar la comunicación.

En el mismo sentido, según Boolaky y Quick (2016) los hallazgos y conclusiones de los auditores son presentados en los informes de auditoría, pero dichos reportes resultan ser cortos y estandarizados, y no reducen la asimetría de información. Discuten acerca de si brindar más información en dichos informes contribuiría a disminuir dicha brecha y si sería utilizada por los directores de los bancos. Sin embargo, 
consideran que mostrar más información sobre riesgos e incertidumbres haría que los usuarios se formasen una opinión desfavorable respecto del contenido de los estados financieros en su conjunto.

Hay otra rama de estudios que consideran limitado el conocimiento proporcionado por los informes de auditoría sobre empresas con dificultades para continuar su actividad (con problemas de empresa en marcha), y que los reportes no se tienen oportunamente para la toma de decisiones. En varias oportunidades los observadores manifiestan que no están satisfechos con la capacidad de la profesión contable para advertir sobre amenazas de fracaso de clientes (Bellovary, Giacomino \& Akers, 2006; Citron \& Taffler, 2001).

Sormunen (2014) realiza un estudio cualitativo exploratorio sobre las percepciones de los analistas de crédito bancario sobre el uso de los reportes de auditoría de estados financieros de PyMEs que cumplen con la condición de empresa en marcha. Los bancos conforman uno de los grupos principales de usuarios de los estados financieros de estas empresas para satisfacer requisitos básicos en la toma de decisiones de préstamo e inversión. No obstante, de las entrevistas realizadas a oficiales de crédito de instituciones financieras de Finlandia, Niemi \& Sundgren (2012) pudo conocer que no aceptarían estados financieros no auditados a pesar de que algunos le dan relativamente poca importancia al informe de auditoría por considerar que aporta más información didáctica sobre la tarea de auditoría que confiabilidad sobre la información financiera. Asimismo, se pudo saber que los oficiales de crédito solamente verifican si la opinión del auditor es califi cada y si la auditoría fue realizada por alguno de los estudios Big4, lo cual les asegura una auditoría de calidad.

Bessell, Anandarajan y Umar (2003) señalan que los bancos no parecen dar importancia adicional al informe del auditor al momento de calificar a un cliente, ya que actualmente cuentan con un conjunto de alternativas de información útil que utilizan de manera significativa, lo cual les permite realizar sus propias investigaciones (Church, Davis \& McCracken, 2008). En el mismo sentido, Ranninger (2013) señala que la información que brinda el informe de auditoría es menos importante para las entidades bancarias porque dichas entidades tienen la posibilidad de acceder a mayor cantidad de información del cliente que otras.

Guiral, Gonzalo y Rodgers (2007) consideran que el informe de auditoría contiene información relevante cuando es contrario a las expectativas financieras favorables. Un estudio realizado por estos autores obtuvo resultados opuestos en cuanto a que, por un lado, los analistas de crédito parecen no otorgar demasiada importancia a los informes de auditoría no calificados (opinión sin modificar o limpia) si cuentan con información adicional que resulta desfavorable para el cliente. Por el contrario, un informe con opinión calificada es causal de un cambio de actitud frente a la evaluación del cliente que solicita el crédito.

Pucheta y Vico (2008) analizaron la utilidad del informe de auditoría en el caso de otorgamiento de crédito por parte de las empresas comerciales. Un estudio realizado en el ámbito de empresas españolas encontró que se considera relevante el informe de auditoría, y que las decisiones de crédito se ven afectadas de diferente manera según la naturaleza de las salvedades de opinión expresadas en él.

\section{El informe de auditoría según las normas aplicables en la Argentina}

La República Argentina es uno de los pocos países en los cuales rigen diferentes normas para un mismo servicio profesional (Español \& Subelet, 2014). Por un lado la Resolución Técnica -RT- No 37 de la Federación Argentina de Consejos Profesionales de Ciencias Económicas -FACPCE- sobre Normas de auditoría, revisión, otros encargos de aseguramiento, certificación y servicios relacionados, y por otra parte, los pronunciamientos emitidos por la International Federation of Accountants -IFAC- por medio del International Ethics Standards Board for Accountants -IESBA- y el International Auditing and Assurance Standards Board -IAASB-, que fueron aprobados mediante las RT 32 a 35 por la FACPCE y son de aplicación obligatoria en la auditoría de estados financieros emitidos obligatoriamente bajo las International Financial Reporting Standards -IFRS- o encargos de revisión sobre estados financieros intermedios de ejercicios anuales auditados con normas internacionales. Para el resto su aplicación es optativa. 
La RT37 surgió en el año 2013, entre otras razones, con el fin de adecuar el tratamiento de diferentes situaciones a lo establecido por las normas internacionales.

"Existe la necesidad manifiesta de que las normas de auditoría (...) sean uniformes y adecuadas a la importancia que tienen para la comunidad, debido a la diversidad de intereses que existe entre todos los usuarios de los estados contables y los entes que los emiten. La satisfacción de esa necesidad asegurará que se logre el ineludible grado de confiabilidad de la información contable, para que la comunidad la utilice como base para orientar adecuadamente sus decisiones." (RT37 de la FACPCE)

Esto denota el objetivo de la auditoría de servir como medio para incrementar la confiabilidad de la información contable en beneficio de los usuarios.

Para los propósitos del presente trabajo, se considera necesario mencionar los distintos tipos de opinión que prevén las normas de auditoría aplicables en el contexto bajo estudio: opinión modificada, que agrupa a las opiniones favorables con salvedades, opinión adversa y abstención de opinión. Por el contrario, la opinión no modificada es la opinión favorable sin salvedades (Español \& Subelet, 2014).

El auditor, para emitir su opinión, deberá evaluar la significación o materialidad y el efecto generalizado, o no, de las incorrecciones que presentan los estados contables. El efecto combinado de ambas variables determinará qué tipo de opinión emitirá. Entonces, si el auditor encuentra que los estados financieros contienen incorrecciones materiales pero los efectos no son generalizados, emitirá una opinión con salvedades; si por el contrario los efectos de dichas incorrecciones son materiales y generalizados, emitirá una opinión desfavorable o adversa.

Por otro lado, si el profesional se encuentra con la imposibilidad de obtener evidencia de auditoría adecuada y suficiente, y el efecto sobre los estados financieros no es generalizado, el auditor emitirá una opinión con salvedades por limitaciones en el alcance; en el caso que dichas limitaciones tengan un efecto generalizado, el auditor se deberá abstener de opinar.

Las normas de auditoría prevén la utilización de un párrafo de énfasis cuando el contador considere necesario llamar la atención de los usuarios sobre alguna otra cuestión que a su juicio es fundamental para una adecuada comprensión de la información y que se encuentre revelada en los estados financieros. En el caso de que dichas cuestiones no estuviesen correctamente expuestas darían lugar a una opinión modificada.

La inclusión del párrafo de énfasis no es obligatoria; depende del criterio del auditor. Enseguida algunos de los supuestos en los cuales correspondería utilizar el párrafo de énfasis: cuando haya incertidumbres respecto al principio de empresa en marcha; cuando los estados financieros hayan sido preparado sobre la base de un marco regulatorio de información contable que no es aceptable para las normas contables profesionales; cuando los estados financieros son modificados por un hecho del que se toma conocimiento después de las fechas originales en que la dirección del ente aprobó los estados financieros y el auditor emitió su informe; cuando el contador considere necesario llamar la atención de los usuarios sobre alguna cuestión que a su juicio es fundamental para una adecuada comprensión de los estados contables.

\section{METODOLOGÍA}

El presente es un estudio de tipo exploratorio-descriptivo, que empleó una metodología de casos múltiples, de tipo no experimental y transversal, con recolección de datos cuantitativos y cualitativos. Hernández, Fernández y Baptista (2010) indican que los estudios de caso confían más bien en una generalización analítica, en vez de una generalización estadística a una población.

Para cumplir con el objetivo propuesto se realizaron entrevistas a 16 analistas, mayoritariamente profesionales en ciencias económicas, que participan del proceso de evaluación del sujeto de crédito en entidades bancarias públicas y privadas, entidades financieras y organizaciones pertenecientes al sector comercial e industrial de la ciudad de Bahía Blanca, Argentina. Esta se encuentra ubicada en el sur de la 
provincia de Buenos Aires y cuenta con una población de 301 mil habitantes, siendo la tercera en importancia de la provincia y la décima de la Argentina (Censo Nacional de la Población, CNP, 2010).

La selección de la muestra de casos se realizó con base en un criterio no probabilístico (o dirigido), es decir, la elección de los elementos no depende de cálculos probabilísticos, sino que tiene relación con las características de la investigación y las decisiones del investigador que construye la muestra (Vazquez, Bongianino, Sosisky \& Albano, 2006). El criterio de selección empleado fue muestreo por conveniencia, a través de contactos en las diversas organizaciones, buscando obtener la representatividad de entidades bancarias, financieras y empresas que brindan crédito comercial a sus clientes. El periodo de recolección de datos abarcó desde febrero de 2017 a marzo de 2018.

Se considera que los participantes de la muestra tienen conocimientos suficientes, además de una vasta experiencia basada en los puestos que ocupan en las respectivas entidades en las cuales analizan clientes de diversos tamaños y actividades. Tienen además acceso a conocimiento compartido que se genera en las grandes organizaciones a las que pertenecen.

Para el desarrollo de las entrevistas se utilizaron cuestionarios estructurados, con preguntas cerradas y respuestas con puntajes según una escala ordinal pre-establecida. Fueron realizadas en forma personal, de modo que el entrevistador pudo ahondar en las respuestas de los profesionales, obteniendo en algunos casos justificaciones a las calificaciones.

El instrumento utilizado para la entrevista fue revisado por especialistas y se aplicó en un caso piloto (Weiss, 1994) mediante la realización de una entrevista a una licenciada en administración y magíster en fi nanzas, perteneciente a una entidad financiera no bancaria, con amplia experiencia en el sector, quien además se desempeña como docente universitaria y ha participado de diversas investigaciones. Como resultado de esta etapa, el cuestionario fue modificado y mejorado.

La versión definitiva del instrumento de recolección de datos consta de dos partes: PARTE A - Descripción del perfil del entrevistado (entidad a la que pertenece, cargo, rango de edad, formación); PARTE B Cuestiones específicas vinculadas a la importancia de la información solicitada para la calificación crediticia, y referidas en particular al informe de auditoría.

La entrevista consistió en calificar de 1 (uno) a 4 (cuatro) según orden de importancia (siendo 1-baja, 2-medianamente baja, 3-medianamente alta y 4-alta) los documentos que se utilizan en el análisis de la entidad para el otorgamiento de financiación, enfocado especialmente en el informe de auditoría y sus diversas alternativas.

Para el análisis de datos se buscó hacer un análisis cuantitativo de las calificaciones obtenidas de los entrevistados en la escala ordinal (Hernández et al., 2010) empleando el software SPSS 22 y Stata 14. Los resultados fueron profundizados y enriquecidos a partir del análisis de las respuestas cualitativas obtenidas.

La confiabilidad del cuestionario se analizó mediante el alfa de Cronbach, que toma un valor global de 0,75 , siendo mayor a 0,7 para cada pregunta individual, lo cual demuestra consistencia entre cada criterio del cuestionario.

El análisis de los resultados se realizó mediante estadística descriptiva (media, mediana, moda y desvío estándar) y el porcentaje de acuerdo. El mismo se calcula considerando positivas las respuestas 3 y 4 (importancia medianamente alta y alta) de la siguiente forma: Kc=VP/VT.

Donde Kc es el coeficiente de consenso, VP son las respuestas positivas por ítem y VT las respuestas totales por ítem (un total de 16). De esta forma se obtiene una medida que resume el porcentaje de entrevistados que consideran relevante el ítem en cuestión (Akiyama, Nolan, Darrah, Rahem, \& Wang, 2016).

La tabla 1 contiene los datos de título profesional, tipo de organización en la que labora, cargo, edad y sexo de las personas que participaron en la investigación. 
TABLA 1A

Perfil de los entrevistados

\begin{tabular}{|c|c|c|c|c|c|c|}
\hline Código & Formación & $\begin{array}{c}\text { Tipo de } \\
\text { Organización }\end{array}$ & $\begin{array}{l}\text { Cargo } \\
\text { actual }\end{array}$ & $\begin{array}{c}\text { Antigüedad en el } \\
\text { cargo }\end{array}$ & Edad & Sexo \\
\hline Caso Piloto & $\begin{array}{l}\text { Licenciado en } \\
\text { Administración }\end{array}$ & Financiera A & $\begin{array}{l}\text { Asesoría } \\
\text { externa }\end{array}$ & 1 año & $<40$ & Mujer \\
\hline $\begin{array}{c}\text { Entrevistado } \\
1\end{array}$ & Contador Público & Banco Privado A & $\begin{array}{l}\text { Gerente de } \\
\text { sucursal }\end{array}$ & 9 años & $\begin{array}{l}\text { Entre } 40 \mathrm{y} \\
50\end{array}$ & Hombre \\
\hline $\begin{array}{c}\text { Entrevistado } \\
2\end{array}$ & Contador Público & Banco Privado B & $\begin{array}{l}\text { Ejecutivo de } \\
\text { empresas }\end{array}$ & 14 años & $\begin{array}{l}\text { Entre } 40 \text { y } \\
50\end{array}$ & Mujer \\
\hline $\begin{array}{c}\text { Entrevistado } \\
3\end{array}$ & Contador Público & Banco Privado B & $\begin{array}{l}\text { Gerente de } \\
\text { sucursal }\end{array}$ & 11 años & $>50$ & Hombre \\
\hline $\begin{array}{c}\text { Entrevistado } \\
4\end{array}$ & $\begin{array}{l}\text { Licenciado en } \\
\text { Administración }\end{array}$ & Banco Privado A & $\begin{array}{l}\text { Oficial banca } \\
\text { PyME }\end{array}$ & 6 años & $<40$ & Mujer \\
\hline $\begin{array}{c}\text { Entrevistado } \\
5\end{array}$ & $\begin{array}{l}\text { Estudiante } \\
\text { Contador } \\
\text { Público }\end{array}$ & Banco Público C & $\begin{array}{l}\text { Oficial banca } \\
\text { empresas }\end{array}$ & 2 años & $<40$ & Mujer \\
\hline $\begin{array}{c}\text { Entrevistado } \\
6\end{array}$ & Contador Público & Banco Público C & $\begin{array}{l}\text { Oficial banca } \\
\text { empresas }\end{array}$ & 1 año & $<40$ & Hombre \\
\hline $\begin{array}{c}\text { Entrevistado } \\
7\end{array}$ & Contador Público & Banco Público D & $\begin{array}{l}\text { Oficial crédito } \\
\text { centro } \\
\text { Regional }\end{array}$ & 17 años & $\begin{array}{l}\text { Entre } 40 \text { y } \\
50\end{array}$ & Mujer \\
\hline $\begin{array}{c}\text { Entrevistado } \\
8\end{array}$ & Contador Público & $\begin{array}{l}\text { Industria } \\
\text { petroquímica }\end{array}$ & $\begin{array}{l}\text { Supervisor de } \\
\text { créditos } \\
\text { y cobranzas }\end{array}$ & 4 años & $<40$ & Hombre \\
\hline
\end{tabular}

Fuente: elaboración propia. 
TABLA 1B

Perfil de los entrevistados

\begin{tabular}{|c|c|c|c|c|c|c|}
\hline Código & Formación & $\begin{array}{c}\text { Tipo de } \\
\text { Organización }\end{array}$ & $\begin{array}{l}\text { Cargo } \\
\text { actual }\end{array}$ & $\begin{array}{c}\text { Antigüedad en el } \\
\text { cargo }\end{array}$ & Edad & Sexo \\
\hline & & & y cobranzas & & & \\
\hline $\begin{array}{c}\text { Entrevistado } \\
9\end{array}$ & Contador Público & Comercio & $\begin{array}{l}\text { Auditoría } \\
\text { Interna }\end{array}$ & 1 año & $<40$ & Mujer \\
\hline $\begin{array}{c}\text { Entrevistado } \\
10\end{array}$ & Contador Público & Financiera B & Gerente & 3 años & $<40$ & Mujer \\
\hline $\begin{array}{c}\text { Entrevistado } \\
11\end{array}$ & $\begin{array}{l}\text { Secundario } \\
\text { completo }\end{array}$ & Banco Privado E & $\begin{array}{l}\text { Oficial Senior } \\
\text { Banca } \\
\text { Empresa }\end{array}$ & 12 años & $\begin{array}{l}\text { Entre } 40 \text { y } \\
50\end{array}$ & Hombre \\
\hline $\begin{array}{c}\text { Entrevistado } \\
12\end{array}$ & $\begin{array}{l}\text { Ingeniero } \\
\text { Agrónomo }\end{array}$ & Empresa Agrícola & $\begin{array}{l}\text { Responsable } \\
\text { Comercial }\end{array}$ & 10 años & $\begin{array}{l}\text { Entre } 40 \text { y } \\
50\end{array}$ & Hombre \\
\hline $\begin{array}{c}\text { Entrevistado } \\
13\end{array}$ & $\begin{array}{l}\text { Licenciado en } \\
\text { Economía }\end{array}$ & Banco Privado F & $\begin{array}{l}\text { Oficial Banca } \\
\text { Empresa }\end{array}$ & 5 meses & $<40$ & Hombre \\
\hline $\begin{array}{c}\text { Entrevistado } \\
14\end{array}$ & $\begin{array}{l}\text { Licenciado en } \\
\text { Administración }\end{array}$ & Banco Privado G & $\begin{array}{l}\text { Gerente de } \\
\text { Sucursal }\end{array}$ & 2 años & $<40$ & Hombre \\
\hline $\begin{array}{c}\text { Entrevistado } \\
15\end{array}$ & Contador Público & Empresa Agrícola & $\begin{array}{l}\text { Responsable } \\
\text { Créditos } \\
\text { Argentina }\end{array}$ & 2 años & $\begin{array}{l}\text { Entre } 40 \text { y } \\
50\end{array}$ & Hombre \\
\hline $\begin{array}{c}\text { Entrevistado } \\
16\end{array}$ & $\begin{array}{l}\text { Licenciada en } \\
\text { Economía }\end{array}$ & Banco Privado A & $\begin{array}{l}\text { Ejecutivo } \\
\text { PyMe }\end{array}$ & 1 año & $<40$ & Mujer \\
\hline
\end{tabular}

Fuente: elaboración propia

\section{RESULTADOS}

\section{Documentación relevante para la calificación crediticia}

En primer lugar, se realizó un análisis de la importancia de los principales documentos requeridos para una calificación crediticia, haciendo una comparación que permitiera determinar la relevancia del informe de auditoría con relación al resto de la documentación. La tabla 2 contiene los puntajes otorgados por los entrevistados a cada uno de los documentos listados, junto con el coeficiente de consenso de cada pregunta. Posteriormente, en la tabla 3 se presenta la estadística descriptiva. 
TABLA 2

Documentación requerida para una solicitud de otorgamiento de crédito

\begin{tabular}{|c|c|c|c|c|c|c|c|c|c|c|c|c|c|c|c|c|c|}
\hline & $\begin{array}{l}\mathrm{E} \\
1\end{array}$ & $\begin{array}{l}\mathbf{E} \\
2\end{array}$ & $\begin{array}{l}\mathbf{E} \\
\mathbf{3}\end{array}$ & $\begin{array}{l}E \\
4\end{array}$ & $\begin{array}{l}\mathbf{E} \\
\mathbf{5}\end{array}$ & $\begin{array}{l}\mathrm{E} \\
6\end{array}$ & $\begin{array}{l}\mathbf{E} \\
7\end{array}$ & $\begin{array}{l} \\
8\end{array}$ & $\begin{array}{l}\mathbf{E} \\
9\end{array}$ & $\begin{array}{c}\mathbf{E} \\
\mathbf{1 0}\end{array}$ & $\begin{array}{c}\mathbf{E} \\
\mathbf{1 1}\end{array}$ & $\begin{array}{c}E \\
12\end{array}$ & $\begin{array}{c}E \\
13\end{array}$ & $\begin{array}{c}E \\
14\end{array}$ & $\begin{array}{c}E \\
15\end{array}$ & $\begin{array}{c}E \\
16\end{array}$ & $\begin{array}{l}\text { IC } \\
(\%)\end{array}$ \\
\hline $\begin{array}{l}\text { Estatuto / } \\
\text { Contrato social }\end{array}$ & 1 & 4 & 4 & 4 & 4 & 3 & 4 & 3 & 3 & 4 & 4 & 4 & 4 & 2 & 2 & 2 & 75 \\
\hline $\begin{array}{l}\text { Estados } \\
\text { contables } \\
\text { auditados }\end{array}$ & 4 & 4 & 4 & 4 & 4 & 4 & 4 & 4 & 4 & 4 & 4 & 4 & 4 & 4 & 4 & 4 & 100 \\
\hline $\begin{array}{l}\text { Actas de } \\
\text { asamblea y } \\
\text { directorio }\end{array}$ & 4 & 4 & 4 & 4 & 4 & 2 & 4 & 4 & 3 & 2 & 4 & 4 & 4 & 4 & 2 & 4 & 81 \\
\hline $\begin{array}{l}\text { Declaraciones } \\
\text { juradas } \\
\text { impositivas } \\
\text { (valor } \\
\text { agregado, } \\
\text { ingresos } \\
\text { brutos, a las } \\
\text { ganancias) }\end{array}$ & 4 & 4 & 4 & 4 & 2 & 1 & 4 & 4 & 3 & 4 & 4 & 4 & 4 & 2 & 3 & 4 & 81 \\
\hline $\begin{array}{l}\text { Declaraciones } \\
\text { juradas de } \\
\text { aportes } \\
\text { previsionales }\end{array}$ & 4 & 2 & 4 & 4 & 4 & 1 & 4 & 4 & 3 & 2 & 3 & 2 & 4 & 2 & 2 & 3 & 63 \\
\hline
\end{tabular}

Nota: Orden de importancia: 1-baja, 2-medianamente baja, 3-medianamente alta, 4-alta. IC: Índice de consenso. Fuente: elaboración propia con datos de la investigación.

TABLA 3

Estadística descriptiva de la documentación requerida

\begin{tabular}{lcccc}
\hline & Media & Mediana & Moda & $\begin{array}{c}\text { Desvío } \\
\text { estándar }\end{array}$ \\
\hline Estatuto / Contrato social & 3,25 & 4 & 4 & 1 \\
\hline Estados contables auditados & 4 & 4 & 4 & 0 \\
\hline Actas de asamblea y directorio & 3,56 & 4 & 4 & 0,814 \\
\hline $\begin{array}{l}\text { Declaraciones juradas impositivas (valor } \\
\text { agregado, ingresos brutos, a las ganancias) }\end{array}$ & 3,44 & 4 & 4 & 0,964 \\
\hline $\begin{array}{l}\text { Declaraciones juradas de aportes } \\
\text { previsionales }\end{array}$ & 3 & 3 & 4 & 1,033 \\
\hline
\end{tabular}

Fuente: elaboración propia con datos de la investigación

Según se puede observar, todos los documentos aquí incluidos son normalmente solicitados a los entes que desean acceder a créditos en cualquiera de los tipos de entidades analizadas (bancarias, financieras no bancarias, industriales, comerciales, agropecuarias). Ello justifica que en todos los casos a partir de la calificación asignada la moda sea de 4 puntos (importancia alta), denotando no solo su relevancia sino también la obligatoriedad de su presentación a fin de que haya cliente y carpeta de crédito posible.

En particular, resulta fundamental contar con estados financieros auditados. Se los calificó como importantes de manera unánime (100\% de los entrevistados otorgaron la máxima puntuación). Como ratificación de lo dicho se puede mencionar que para los Entrevistados 1, 2 y 6 su presentación es obligatoria 
en la mayoría de los casos, incluso para la apertura de una carpeta o cuenta. Por su parte, el Entrevistado 3 manifestó que los estados financieros y su información son fundamentales para la clasificación de los deudores y la calificación crediticia.

Se aclaró en dos casos que no es suficiente la presentación de los estados financieros; los mismos deben estar acompañados por el informe de auditoría (Entrevistados 2, 7). Aunque en ciertos casos se acepta la presentación con una certificación literal, siempre se prefiere que los mismos estén auditados (Entrevistado 13). De lo manifestado se puede concluir que el informe de auditoría es considerado como documentación relevante para la calificación crediticia.

Los estados financieros son la base sobre la cual se realizarán los análisis para determinar el monto del crédito a otorgar. En el caso de las entidades bancarias es requisito del Banco Central de la República Argentina su presentación para la apertura de la carpeta de crédito y comenzar a analizar a la entidad solicitante.

Las entidades no bancarias también consideran fundamentales a los estados financieros auditados. Por ejemplo, el Entrevistado 8 (perteneciente al área de crédito de la industria petroquímica) señala que son indispensables, otorgando a los clientes un plazo de 6 meses desde la fecha de cierre de ejercicio económico para su presentación. El entrevistado 10 (perteneciente a una entidad financiera no bancaria) se expresó en el mismo sentido.

El estatuto o contrato social también es considerado un documento importante, requisito formal indispensable (Entrevistado 2) para la apertura de una carpeta de crédito. El 56,25\% de los entrevistados lo consideran importante y el 18,75\% medianamente importante; otro $18.75 \%$ de importancia medianamente baja y sólo el Entrevistado 1 (6,25\%) le otorga una importancia baja; al respecto argumentó que el mismo sólo cumple requisitos formales y no influye en la decisión de otorgamiento del crédito. Los Entrevistados 5 y 7 coincidieron con esta afirmación. Los entrevistados 4, 10, 13 y 14 mencionaron que es útil a los efectos de conocer quiénes son los integrantes de las sociedades a calificar, por ejemplo, para solicitar garantías para los futuros créditos que pudieran otorgarse.

Las actas de asamblea y directorio son consideradas importantes, incluso más que el acta constitutiva. Aquí 12 entrevistados las consideraron importantes (el 75\%) y un solo entrevistado de importancia relativamente alta $(6,25 \%)$. Los tres restantes las calificaron como de importancia relativamente baja $(18,75 \%)$. Estas son requeridas en todos los casos (Entrevistado 1), siendo útiles para el conocimiento del cliente (Entrevistado 2) y de quién tiene la capacidad de tomar créditos a nombre de la entidad -personas autorizadas a firmar en su nombre y crear responsabilidades a la firma- (Entrevistados 6, 8, 10, 16); allí radica su importancia. Estos entrevistados consideran que no tienen influencia directa con el monto del posible crédito a otorgar, al igual que sucede con la presentación del acta constitutiva.

El Entrevistado 3, gerente de un banco privado, consideró relevante esta documentación como respaldo de las decisiones adoptadas dentro de la sociedad. Según indicó, cuando el nivel de endeudamiento es significativo se requiere que todas las decisiones se vuelquen en actas; también en caso de que hubiera renovación de mandatos, se solicitan las actas que lo avalen.

Del mismo modo, las actas permiten conocer la marcha de la empresa, las autoridades a cargo, las políticas de distribución de resultados, entre otras cuestiones que pudieran afectar a la entidad bancaria (Entrevistado 5), así como los hechos posteriores a la fecha de los estados financieros que fueran de su interés (Entrevistado 7).

En cuanto a la presentación de declaraciones juradas de cumplimiento fiscal, se justifica en cuanto respaldan la información contable y permiten ver, desde una fuente confiable, la evolución de la entidad luego del cierre del ejercicio (Entrevistado 10). A su vez permiten estimar el nivel de ingresos y facturación de la firma postulante en el caso de las declaraciones de impuestos (Entrevistado 3).

Las declaraciones juradas previsionales tienen un matiz que las distingue de las demás, con la mayor dispersión y el menor índice de consenso en las respuestas. Las entidades bancarias pueden obtener por 
sí mismas información acerca de las deudas previsionales de sus clientes. Su evaluación permite conocer el comportamiento del cliente respecto de sus obligaciones de pago (Entrevistado 6); el incumplimiento de dichas obligaciones automáticamente descarta al sujeto de crédito (Entrevistados 2, 3, 7) o reducen la calificación otorgada al cliente si se encuentran incluidas en un plan de pagos (Entrevistado 5). Las entidades financieras no bancarias utilizan esta documentación como parámetro del tamaño de la firma, estimado a partir de su masa laboral.

En resumen, todos los documentos aquí mencionados fueron considerados importantes, aunque no todos ellos brinden información igualmente relevante para la toma de decisiones en cuanto a la calificación crediticia y al otorgamiento de financiación a empresas.

\section{Importancia y utilidad percibida respecto de un informe de auditoría}

Según se mencionó en el apartado anterior, los estados financieros auditados son un documento relevante para la evaluación del otorgamiento de crédito en las entidades analizadas. En la Tabla 4 se exponen las respuestas obtenidas en relación con la opinión de los entrevistados respecto del informe de auditoría (IA) y en la Tabla 5 la estadística descriptiva correspondiente.

TABLA 4

Opinión sobre el informe de auditoría

\begin{tabular}{|c|c|c|c|c|c|c|c|c|c|c|c|c|c|c|c|c|c|}
\hline Informe de Auditoría (IA) & $\begin{array}{l}\mathbf{E} \\
1 \\
\end{array}$ & $\begin{array}{l}\mathbf{E} \\
2\end{array}$ & $\begin{array}{l}\mathbf{E} \\
\mathbf{3} \\
\end{array}$ & $\begin{array}{l}E \\
4 \\
\end{array}$ & $\begin{array}{l}\mathbf{E} \\
\mathbf{5}\end{array}$ & $\begin{array}{l}E \\
6 \\
\end{array}$ & $\begin{array}{l}\mathbf{E} \\
7\end{array}$ & $\begin{array}{l}\mathbf{E} \\
8\end{array}$ & $\begin{array}{l}\mathbf{E} \\
9\end{array}$ & $\begin{array}{l}\mathbf{E} \\
10\end{array}$ & $\begin{array}{l}E \\
11 \\
\end{array}$ & $\begin{array}{l}E \\
12\end{array}$ & $\begin{array}{l}E \\
13\end{array}$ & $\begin{array}{l}E \\
14\end{array}$ & $\begin{array}{l}E \\
15\end{array}$ & $\begin{array}{l}E \\
16\end{array}$ & $\begin{array}{l}\text { IC } \\
\text { (\%) }\end{array}$ \\
\hline $\begin{array}{l}\text { ¿Qué grado de comprensión } \\
\text { tiene Ud. de la información } \\
\text { que brindan los informes de } \\
\text { auditoría? }\end{array}$ & 4 & 4 & 4 & 2 & 2 & 4 & 4 & 4 & 4 & 4 & 4 & 3 & 2 & 2 & 4 & 3 & 75 \\
\hline $\begin{array}{l}\text { ¿Qué uso le da al IA que } \\
\text { contiene una opinión } \\
\text { modificada por limitación } \\
\text { en el alcance de su trabajo? }\end{array}$ & 4 & 2 & 3 & 1 & 4 & 4 & 4 & 1 & 3 & 1 & 4 & 1 & 3 & 4 & 4 & 2 & 63 \\
\hline $\begin{array}{l}\text { ¿Qué uso le da al IA que } \\
\text { contiene una opinión } \\
\text { modificada por } \\
\text { discrepancias en alguna } \\
\text { norma de valuación o } \\
\text { exposición? }\end{array}$ & 4 & 3 & 2 & 3 & 4 & 4 & 2 & 1 & 3 & 1 & 2 & 1 & 3 & 1 & 4 & 2 & 50 \\
\hline \multicolumn{18}{|c|}{ Qué uso le da al IA que tiene un párrafo de énfasis sobre: } \\
\hline $\begin{array}{l}\text { a) Problemas de empresa en } \\
\text { marcha }\end{array}$ & 4 & 4 & 3 & 1 & 4 & 4 & 4 & 1 & 3 & 1 & 4 & 4 & 4 & 4 & 4 & 3 & 81 \\
\hline $\begin{array}{l}\text { b) Incertidumbres (juicios, } \\
\text { renovación de concesiones, } \\
\text { ajuste tarifas, etc.) }\end{array}$ & 4 & 3 & 4 & 1 & 3 & 3 & 4 & 1 & 3 & 3 & 4 & 4 & 4 & 4 & 4 & 4 & 88 \\
\hline $\begin{array}{l}\text { ¿Qué nivel de credibilidad } \\
\text { cree Ud. que la opinión de } \\
\text { un auditor agrega a la } \\
\text { información que brindan los } \\
\text { estados contables? }\end{array}$ & 4 & 4 & 1 & 4 & 3 & 2 & 4 & 1 & 4 & 3 & 4 & 3 & 2 & 4 & 4 & 2 & 69 \\
\hline $\begin{array}{l}\text { ¿Considera que si el auditor } \\
\text { pertenece a uno de las Big4, } \\
\text { la entidad le otorgará mayor } \\
\text { importancia a su opinión } \\
\text { sobre los EECC? }\end{array}$ & 4 & 3 & 4 & 3 & 1 & 2 & 2 & 1 & 4 & 1 & 2 & 4 & 4 & 3 & 4 & 2 & 56 \\
\hline
\end{tabular}


TABLA 5

Estadística descriptiva de la opinión del informe de auditoría

\begin{tabular}{lcccc}
\hline Informe de Auditoría (IA) & Media & Mediana & Moda & Des. estándar \\
\hline $\begin{array}{l}\text { iQué grado de comprensión tiene Ud. de la información } \\
\text { que brindan los informes de auditoría? }\end{array}$ & 3,38 & 4 & 4 & 0,885 \\
\hline $\begin{array}{l}\text { iQué uso le da al IA que contiene una opinión modificada } \\
\text { por limitación en el alcance de su trabajo? }\end{array}$ & 2,81 & 3 & 4 & 1,276 \\
\hline $\begin{array}{l}\text { iQué uso le da al IA que contiene una opinión modificada } \\
\text { por discrepancias en alguna norma de valuación o } \\
\text { exposición? }\end{array}$ & 2,50 & 2,5 & 4 & 1,155 \\
\hline $\begin{array}{l}\text { Qué uso le da al IA que tiene un párrafo de énfasis sobre: } \\
\text { a) ¿Problemas de empresa en marcha? }\end{array}$ & 3,25 & 4 & 4 & 1,183 \\
\hline $\begin{array}{l}\text { b) ¿Incertidumbres (juicios, renovación de concesiones, } \\
\text { ajuste tarifas, etc.)? }\end{array}$ & 3,31 & 4 & 4 & 1,014 \\
\hline $\begin{array}{l}\text { iQué nivel de credibilidad cree Ud. que la opinión de un } \\
\text { auditor agrega a la información que brindan los estados } \\
\text { contables? }\end{array}$ & 3,06 & 3,5 & 4 & 1,124 \\
\hline $\begin{array}{l}\text { ¿Considera que si el auditor pertenece a una de las Big4, } \\
\text { la entidad le otorgará mayor importancia a su opinión } \\
\text { sobre los EECC? }\end{array}$ & 2,75 & 3 & 4 & 1,183 \\
\hline
\end{tabular}

Fuente: elaboración propia con datos de la investigación.

En primer lugar, se pretendió evaluar el grado de comprensión que cada entrevistado consideraba tener respecto de la información que brinda un informe de auditoría. Siendo en su mayoría profesionales de formación contador público, era de esperar que su nivel de comprensión fuera alto. El 62,50\% de los entrevistados respondió en este sentido.

Sin embargo, el 25\% de los entrevistados dijo tener un nivel de comprensión medianamente bajo del IA (Entrevistados 4, 5, 13, 14). Se trata de oficiales de crédito cuya formación no profundiza en el contenido de los IA: dos licenciados en administración, un licenciado en economía y una estudiante de la carrera de contador público, que por su nivel de avance en los estudios universitarios aún no había aprobado la materia Auditoría. El 12,50\% restante, aun no siendo contadores públicos, mencionó tener una comprensión medianamente alta.

Cabe remarcar los casos de los entrevistados 11, 12 y 16 -con formación distinta a la de contador- que acusan un grado de comprensión medianamente alto o alto; la misma ha sido obtenida dada su experiencia en el sector de análisis de créditos. Sin embargo, dicha situación afecta su percepción respecto de informes con opinión modificada porque, según ellos, han visto opiniones limpias y la falta de conocimientos técnicos dificulta la comprensión de las diferentes causas que originan la modificación de la opinión.

Se distingue entonces la valoración otorgada según la formación del analista de crédito. Quienes poseen formación de contador público están en condiciones de interpretar de mejor manera los informes de auditoría y la opinión del auditor y, en consecuencia, le dan una mayor importancia. Por el contrario, los oficiales de crédito entrevistados con una formación distinta, en general, no tenían conocimientos respecto del mismo y no lo valoraban del mismo modo.

Igualmente, se observa que en algunos casos las opiniones respecto de la importancia del informe de auditoría para el otorgamiento de créditos parecen variar según la posición ocupada por el entrevistado dentro de la entidad. Por ejemplo, quienes se encuentran en funciones del tipo operativas, suelen dar más importancia a cuestiones de tipo formal -v.gr., la falta de un documento- mientras que quienes ocupan altos puestos 
analizan globalmente la información, y en caso de omisión, priorizan la importancia de la documentación solicitada y el tipo de información que brinda.

\section{Evaluación de acuerdo con el tipo de informe de auditoría}

En este apartado se busca analizar la importancia que tiene para los analistas de crédito la inclusión de una opinión modificada o de un párrafo de énfasis en el IA. Esto es, si el hecho de que la opinión no sea limpia o que existan situaciones que deben llamar la atención de los analistas modifica la valoración que hacen respecto del IA.

Tal como se puede visualizar, la mayoría de los entrevistados calificaron a los informes con opinión modificada o párrafo de énfasis como importantes. En todos los casos la moda resultante del análisis de las respuestas es 4 (importancia alta); sin embargo, el desvío y el índice de conformidad demuestran que hay variaciones en las calificaciones de cada tipo de informe.

En concordancia con lo encontrado en el presente trabajo, Martínez y Martínez (2008) observaron que el tipo de informe de auditoría afecta las decisiones que deben tomar los agentes en las operaciones comerciales. Por su parte, Sormunen (2014) señala que los informes de auditoría serán especialmente útiles cuando tengan una opinión diferente a la estándar, en caso contrario los analistas tienden a utilizar otras fuentes de información para sus decisiones.

Es decir, aquellos informes que contienen alertas sobre discrepancias respecto al marco de información contable, limitaciones al trabajo del auditor o situaciones que deben llamar la atención del usuario de la información contable son valorados por analistas para la calificación crediticia. Según se verá más adelante, encontrar este tipo de informes aumenta la confianza que los funcionarios depositan en los informes de auditoría y les permitiría tomar mejores decisiones, coincidiendo con los resultados obtenidos por Guiral, Gonzalo y Rodgers (2007). Sin embargo, existen casos en los que las valoraciones no son tan altas.

Analizando por sector, los entrevistados que pertenecen a bancos públicos o privados (Entrevistados 1, 2, $3,5,6,7,11,13,14,16)$ califican como importantes estos informes y los utilizan en su proceso decisorio. Únicamente la Entrevistada 4, de formación Licenciada en Administración y cargo Oficial de Banca PyME, otorga una puntuación menor; según se ha mencionado, por su formación podría no valorar en forma alta este tipo de informes. Además, ha expresado no tener una comprensión elevada de la información del informe de auditoría. En el resto de los sectores las opiniones son variadas.

- El Entrevistado 8, supervisor de créditos y cobranzas de la industria petroquímica, otorga la mínima calificación a todos los tipos de informes; es evidente que el IA no le resulta una fuente de información relevante para la toma de sus decisiones. Sin embargo, no es posible concluir que por su única opinión esto sea así para todas las empresas industriales, más aun considerando que había calificado como de importancia alta la disponibilidad de los estados financieros auditados, según se vio en el apartado anterior;

- El Entrevistado 10, gerente de una entidad financiera no bancaria, únicamente considera como relevantes los informes que enfaticen situaciones de incertidumbre que afecten al ente en cuestión;

- El Entrevistado 9, perteneciente a una empresa comercial, valora todas las alternativas de informes con opiniones calificadas o párrafos de énfasis como medianamente importantes;

- Los Entrevistados 12 y 15 pertenecen a la misma organización agropecuaria pero otorgan diferentes calificaciones a los informes con opiniones modificadas. Esto se muestra en concordancia con lo expresado anteriormente en cuanto a posición en la organización y formación del entrevistado. Sin embargo, coinciden en que los informes con párrafo de énfasis son de suma importancia.

En suma, las valoraciones cambian según el tipo de modificación en la opinión o la causa que origina la inclusión de un párrafo de énfasis. 
Seguidamente se exponen los resultados vinculados con los informes de auditoría con opiniones calificadas. El efecto sobre el informe de auditoría es que se incluye una explicación en el párrafo de Fundamentos de la opinión, y se redacta la opinión en consecuencia.

El Entrevistado 6 hizo una apreciación que se considera relevante al respecto: menciona que es poco habitual que se presenten informes que no sean limpios. Él consideraría útil estos tipos de IA calificados, dado que ayudarían al momento de evaluar al cliente: si el auditor llegara al punto de dar una opinión modi ficada, significaría que según su juicio los estados financieros presentan errores o discrepancias graves, de modo que deberían ser descartados como fuente de información para la calificación crediticia.

El Entrevistado 8, quien se desempeña en el área de créditos de una industria petroquímica, hace una crítica severa al respecto:

"No aplica, en el sentido de que los informes hoy por hoy son copiar y pegar. En el caso de que se hicieran a conciencia, serían de relevancia 4. Pero de 1500 balances que he visto, nunca vi ninguna salvedad." (Entrevistado 8

El Entrevistado 10, perteneciente a una entidad financiera no bancaria, menciona: "Es una salvedad que se dice en voz alta pero no se da en la realidad".

Y finalmente el Entrevistado 13, perteneciente a una entidad bancaria privada, sentencia: "Desde el punto de vista bancario uno mira que está el informe de auditoría y que esté la oblea[1], no se lo lee demasiado. Se fija que esté solamente". (Entrevistado 13.

Las apreciaciones de estos entrevistados llevan a reflexionar si en la actualidad el auditor cumple realmente su rol y en la necesidad de revalorizar la función de la auditoría. Dado que su objetivo primordial es brindar confiabilidad a la información contable, esta percepción de los entrevistados denotaría que no se está cumpliendo.

Por otro lado, el Entrevistado 7 mencionó que no toda salvedad reviste el mismo nivel de importancia, sino que el análisis debe realizarse distinguiendo el tipo de salvedad y las causas que dieron lugar a la misma, dado que afectan de distinto modo la consideración que se haga de los estados financieros auditados y la información contenida en ellos.

En consecuencia, se distinguieron las dos posibles causas:

\section{Caso de opinión modificada por limitación en el alcance}

Se encontró que este ítem es considerado importante, con una moda de 4 y una mediana de 3, justificándose en 7 entrevistados (43,75\%) que consideran relevante un IA con opinión modificada por esta razón y 3 (18,75\%) que lo consideran medianamente relevante; ellos representan el 62,50\% del total. El resto de los entrevistados (37,50\%) lo calificaron como poco o nada importante.

Según el Entrevistado 5 este tipo de informe influye en la evaluación de la empresa, dado que la confiabilidad de la información es menor.

$\mathrm{Al}$ respecto, el Entrevistado 1 mencionó que frente a una situación como esta se da lectura completa al informe y se analiza cual es la causa de la limitación en el alcance mencionada; luego, dependiendo de su relevancia, se analiza el nivel de importancia que tiene para la opinión del analista respecto de los estados financieros.

Según el Entrevistado 3, en consonancia con el Entrevistado 14, los informes de auditoría con limitaciones en el alcance son considerados importantes en el caso de clientes con créditos mayores a $\$ 600.000$,oo; de lo contrario, la relevancia de este tipo de informes es menor. Todas las situaciones mencionadas demuestran que la importancia y utilidad de la documentación solicitada a los clientes muchas veces varía según el tamaño del cliente y el monto del crédito a otorgar. 


\section{Caso de opinión modificada por discrepancia en la aplicación de normas contables de valuación o exposición}

Aquí observamos mayor variabilidad en las respuestas de los entrevistados: la mediana resultante es de 2,5, distinto del valor 4 obtenido por la moda, en contraposición con la cercanía entre ambos valores que se observa en el resto de las cuestiones analizadas en este apartado. Este ítem es considerado de menor relevancia, justificándose en sólo 4 entrevistados (25\%) que consideran de importancia alta un informe de auditoría -IA- con opinión modificada por esta razón, y 4 que lo consideran medianamente importante (25\%), representando entre ambos a la mitad de los entrevistados. El resto de los entrevistados lo calificaron como medianamente importante (25\%) o de importancia baja (25\%).

Una posible causa es que el sustento de la decisión para el otorgamiento del crédito no está basado únicamente en los activos y resultados pasados de la organización (expuestos en los EECC, que muestran información histórica) sino en los futuros flujos de fondos que generará y con los que podrán hacer frente al nuevo pasivo. Adicionalmente, aquellas organizaciones que tienen como actividad principal la prestación de servicios no cuentan con un patrimonio que justifique darle relevancia a este ítem.

Según el Entrevistado 5:

"Aquí se analiza la discrepancia: si es de exposición no se le presta tanta atención, pero en el caso de ser de valuación se podrían enviar peritos bancarios o hacer previsiones al respecto (no tenerlo en cuenta), por ejemplo, si se debe a revaluaciones de inmuebles." (Entrevistado 5)

Los entrevistados 7 y 10 explican que estos IA reciben una calificación menor respecto de los que poseen opinión modificada por limitaciones en el alcance, dado que las deficiencias en la valuación pueden ser suplidas por otras fuentes de información. Los bancos cuentan con sus propias normas de valuación y en algunos casos existen herramientas del mercado para valuar muchos de los elementos del patrimonio de los entes.

A los entrevistados también se les indagó sobre la utilidad de los informes con párrafo de énfasis. En primer lugar, se analizó el caso de su inclusión por problemas de empresa en marcha que hubieran sido correctamente expuestos y considerados por la administración del ente en la elaboración de los estados contables -EECC-.

En este caso se encontró que este ítem es considerado importante por los analistas de crédito. Se observa que diez de los entrevistados (62,50\%) le otorgaron la máxima calificación y tres $(18,75 \%)$ lo consideraron medianamente importante, representando el $81,25 \%$ de las respuestas. Mientras que los otros tres entrevistados (18,75\%) lo calificaron como de importancia muy baja. Esto no coincide en principio con los antecedentes mencionados en el marco teórico.

Es relevante señalar que los entrevistados que dan menores calificaciones son aquellos que pertenecen a entidades financieras no bancarias (en dos de los casos) y el restante pertenece a la entrevistada que por su formación ajena al contenido del IA no acusaba conocimientos fuertes respecto a los casos analizados.

El Entrevistado 10, quién desarrolla su labor en una empresa del tipo comercial y es uno de los que otorgó el nivel de importancia bajo a este caso, justifica su calificación diciendo que no recuerda haber visto nunca un párrafo de énfasis por problemas de empresa en marcha y que de todos modos los créditos que su entidad otorga son de corto plazo (no mayores a 90 días), dónde evalúa las posibilidades de ingresos futuros por otros medios.

En oposición, el Entrevistado 5, perteneciente a una entidad bancaria pública, señala que la existencia de problemas de empresa en marcha es fundamental para la decisión de otorgamiento de crédito. Si el ente postulante presenta dificultades de este tipo se lo descarta inmediatamente como cliente. En concordancia, el Entrevistado 7 remarca que se evalúa la capacidad de repago de la entidad solicitante y lo expuesto anteriormente puede limitar dicha posibilidad.

Por otro lado, se consideraron los casos de informes de auditoría con párrafos de énfasis sobre incertidumbres -que no sean sobre problemas de continuidad de la empresa-correctamente reveladas en los 
estados financieros, pero sobre las cuales el auditor quisiera llamar la atención del usuario de la información contable.

Nuevamente este tipo de informe de auditoría es considerado importante por los entrevistados: 14 lo consideraron medianamente importante $(31,25 \%)$ o importante $(56,25 \%)$, totalizando el $87,50 \%$ de los analistas, y solo en $2(12,50 \%)$ casos se calificó como de importancia baja al párrafo analizado.

$\mathrm{Al}$ analizar las implicancias que podría tener este párrafo de énfasis, el Entrevistado 5 señala que, si las incertidumbres son, por ejemplo, respecto a la resolución de juicios laborales, podría ser un motivo de descarte de la carpeta de crédito. En este mismo sentido, el Entrevistado 1 señala que especialmente para las PyMes es un hecho fundamental la resolución de dichas incertidumbres, ya que puede llevar a la desaparición de la entidad solicitante. Del mismo modo, el Entrevistado 14 menciona que si las incertidumbres son respecto de concesiones obtenidas por la empresa analizada, se realiza un examen de los contratos y de la posibilidad futura de continuación de las mismas.

\section{El rol de la auditoría de estados financieros: credibilidad y prestigio}

Respecto de la credibilidad que otorga la opinión de un auditor a la información que brindan los estados contables, observamos que el $50 \%$ del total de los entrevistados consideran que es alta y el $18,75 \%$ medianamente alta (sumando el $67,75 \%$. El 18,75\% la ponderan como medianamente baja y el $12,50 \%$ como baja. Se observa en este caso una discrepancia en la calificación según el tipo de entidad a la que pertenece el entrevistado. Por un lado, las entidades bancarias le dan la máxima puntuación, pero en el caso de las entidades no bancarias se observa que la calificación es diametralmente opuesta.

El fundamento dado por los entrevistados de estas últimas entidades indica que en el contexto económico actual la información sobre la que se trabaja es inadecuada por ser antigua (los estados financieros se refieren a información histórica y por el grado de informalidad de la economía. Además, los estados financieros auditados no reflejan necesariamente los posibles negocios posteriores al cierre del ejercicio, como por ejemplo una concesión que requerirá de una inyección de fondos y que a su vez asegurará un flujo de dinero que permitirá el repago, es decir, el otorgamiento de financiación.

Por otra parte, el Entrevistado 3 acota:

La información a valores contables a veces difiere de los valores reales, fundamentalmente en bienes de uso y en activos con cotización. Más aun con la inflación. Como el auditor da su opinión sobre productos que no son tan reales, quizá la opinión no es tan confiable, tiene importancia relativa. No así si refleja algún tema puntual como empresa en marcha, juicio, concesiones etc. (Entrevistado 3

El Entrevistado 2 señala además que la credibilidad se ve influenciada por el contador que realiza la auditoría, más en la ciudad de Bahía Blanca, dónde se conoce la forma de trabajar de los profesionales. Es decir, la auditoría debe ser de calidad para brindar confiabilidad a los usuarios de la información financiera. Si el encargo es desarrollado por un profesional que no pareciera ser independiente, o que no es diligente, responsable y meticuloso en el desarrollo del trabajo, su labor no aporta la credibilidad de la información.

En el mismo sentido el Entrevistado 13 agrega:

Debería ser superior [la credibilidad que otorga el IA]. Según mi experiencia, termina siendo un documento que se anexa, que es copy - paste y quedan dudas si el trabajo del auditor es realizado o no. Se ve en algunos casos la falta de independencia. Quita mucha credibilidad que el mismo contador pueda auditar su trabajo, como sucede en Argentina, aunque sea muy buen contador. (Entrevistado 13

El Entrevistado 6 marca que la pérdida de credibilidad se debe a que sólo se observan informes limpios, lo que hace dudar de la verdadera labor del auditor. En el mismo sentido el Entrevistado 8 señala que, si el IA fuese percibido como el resultado de un trabajo realizado en la forma debida y esperada, sería calificado con el máximo nivel de importancia. 
En relación con lo anterior, se pretendió conocer si el hecho de que el IA fuera emitido por uno de los grandes estudios de auditoría conocidos como Big4 incrementaría el nivel de confianza o utilidad del informe de auditoría, teniendo una influencia distinta en la consideración de los estados financieros auditados en la decisión de otorgamiento de crédito.

Este factor fue considerado de importancia baja o medianamente baja por el 43,75\% de los entrevistados (18,75\% y $25 \%$ respectivamente para cada calificación), contrariamente a lo encontrado por Sormunen (2014) en Finlandia. Sólo seis de los entrevistados (37,50\%) le otorgaron el nivel de importancia más alto y tres $(18,75 \%)$ un nivel de importancia relativamente alto. Se observó que los entrevistados no ponderan de sobremanera dichas firmas, sino que le otorgan la misma validez que una firma de menor tamaño.

En principio ello puede justificarse en que el presente estudio ha sido realizado en una ciudad del interior del país, en la que muchas de las empresas que solicitan crédito son Pymes, que contratan estudios contables locales que elaboran los estados financieros y los auditan. A su vez, los grandes estudios de auditoría no tienen representación en la ciudad. Esto conlleva a que, en general, los estados financieros considerados por los analistas de crédito no sean auditados por alguna de las Big4. Estos resultados permiten conocer la relevancia dada a los Big4 en contextos donde no están presentes. A su vez, al no tratarse de una ciudad con gran volumen poblacional, los analistas pueden conocer a los profesionales que realizan los trabajos de auditoría y no requieren del prestigio de las grandes firmas.

Los entrevistados que le otorgan una calificación mayor fundamentan su opinión en el prestigio y percepción de calidad que ostentan dichas compañías que llevan al analista a otorgarle mayor confianza a la opinión expresada.

\section{CONSIDERACIONES FINALES}

El presente artículo expone los resultados de la investigación empírica realizada con el propósito de conocer los factores que afectan la calificación crediticia y las decisiones de otorgamiento de crédito a cargo de analistas de diversos sectores. En particular, se pretendió determinar si la información que brindan los informes de auditoría es relevante para el otorgamiento de crédito en un contexto donde la normatividad exige la presentación de estados financieros auditados a todos los entes.

En primer lugar, se analizó la importancia de diversos documentos de presentación habitualmente obligatoria para una calificación crediticia. Los estados financieros auditados fueron calificados como importantes para la decisión de crédito en este punto. En el caso del estatuto o contrato social y las actas de asamblea o directorio, se pudo conocer que, en general, no influyen en la decisión de otorgamiento y monto del crédito; es decir, no siempre son realmente útiles a los efectos de tomar una decisión, sino que en algunos casos cumplen requisitos formales. Finalmente, las declaraciones juradas impositivas y previsionales parecieran brindar información sobre nivel de ingresos y grado de cumplimiento de las obligaciones por parte del postulante.

Del análisis de la documentación requerida para la calificación crediticia se pudo verificar que todos los documentos identificados fueron considerados importantes, aun cuando no todos brindan información igualmente relevante para la toma de decisiones en cuanto a la calificación crediticia y el otorgamiento de financiación.

La presentación de estados financieros auditados no solo es obligatoria sino también fundamental para la calificación crediticia en todas las entidades a las que pertenecen los analistas. Según los resultados obtenidos, los analistas consideran que el informe de auditoría otorga cierta credibilidad a la información financiera, con algunas consideraciones que se mencionan a continuación.

Respecto de los tipos de opinión, la existencia de opiniones calificadas es una alerta para los analistas de crédito, lo mismo que informes con párrafos de énfasis. La aparición de esta información sería muy útil 
para las decisiones a adoptar. Los resultados encontrados coinciden con los antecedentes de otros trabajos de investigación. Como señalan Guiral y Ruiz-Barbadillo (2011) y Sormunen (2014), este tipo de opinión es el primer filtro o alerta para los analistas de crédito. En concordancia, Ranninger (2013) señala que la opinión calificada tendrá mayor efecto si incluyera cuestiones económicas. Sin embargo, los entrevistados mencionaron que, en general, los informes a los que han tenido acceso son limpios, es decir, no se han encontrado frente a informes de auditoría con opiniones modificadas o párrafos de énfasis.

Los usuarios externos de los estados financieros entrevistados en muchos casos descreen de los informes de auditoría, ya sea por cuestiones vinculadas a la falta de independencia de los contadores respecto de sus clientes, la inexistencia de informes con opinión modificada, la falta de diligencia de los contadores en el desarrollo de los encargos de auditoría. Esto conlleva una percepción de pérdida de calidad en la realización de dicho documento dentro del análisis crediticio y esta percepción conduce a que aumente el costo del crédito a tomar (Karjalainen, 2011; Mansi, Maxwell \& Miller, 2004; Guiral \& Ruiz-Barbadillo, 2011). Sormunen (2014) advirtió que los usuarios tienden a tener una opinión adversa si dudan de la capacidad e independencia del auditor para realizar su trabajo.

Otro punto por resaltar se refiere a las diferencias de valoración que se otorga al informe de auditoría de acuerdo con la formación y cargo del analista de crédito. Los contadores públicos y personas de altos cargos parecieran utilizarlos y valorarlos más respecto de quienes poseen otra formación (que pueden no comprender la información resumida que presentan) y respecto de quienes ocupan cargos operativos, que tal vez no tienen a su cargo la decisión de calificación del cliente, y lo ven más como un requisito formal. Este resultado preliminar presenta una línea de investigación futura mediante la ampliación de la muestra incluyendo profesionales con distinta formación.

Respecto de las limitaciones del estudio, vale mencionar que si se entrevistaran a personas de entidades en ciudades de mayor tamaño o con otra composición empresarial, los resultados podrían haber sido diferentes. Otra limitación es el sesgo de formación profesional, dado que la mayoría de los entrevistados provienen de la misma casa de altos estudios. Finalmente, si bien el estudio de casos múltiples permitió profundizar en el análisis de acuerdo con los objetivos planteados, las conclusiones aquí obtenidas no son generalizables.

En el futuro puede ser interesante profundizar el análisis de datos obtenidos de analistas de créditos pertenecientes a empresas que no sean bancos (entidades financieras no bancarias, industrias, comercios dado que en la muestra que se analiza en este trabajo sólo se pudo entrevistar a seis personas pertenecientes a cada uno de estos tipos de entidades.

Además, por lo observado en las entrevistas, sería interesante profundizar en el análisis de las percepciones de los analistas de acuerdo con su formación, y analizar las capacitaciones que se les brinda a los analistas de crédito en cuanto a la normativa aplicable en los informes de auditoría y las modificaciones que las mismas sufren, ya que se ha observado que el conocimiento técnico evidenciado no ha sido el óptimo en ciertos entrevistados.

Por último, queda pendiente analizar la relación entre la percepción de falta de calidad del trabajo del auditor y el hecho de que en la legislación actual argentina, en contraposición con las normas internacionales, se permita que el contador que lleva la contabilidad de la organización pueda ser el mismo que la audite, ya que, según se pudo observar en las entrevistas, es percibido por el usuario externo como una falta de independencia que reduce su objetividad de manera insalvable.

En conclusión, y en relación con la pregunta de investigación planteada, los informes de auditoría resultan relevantes para las entidades que otorgan financiamiento, pero con ciertas reservas. Se requiere una mayor investigación y superar algunas dificultades vinculadas con la credibilidad de la tarea del auditor, y en consecuencia de sus informes, para que se cumpla el objetivo final de la auditoría, que es precisamente incrementar la confiabilidad de la información financiera para la toma de decisiones de los terceros usuarios de los estados contables. 


\section{Referencias}

Akiyama, Y., Nolan, J., Darrah, M., Rahem, M., \& Wang, L. (2016). A method for measuring consensus within groups: An index of disagreement via conditional probability. Information Sciences, 345, 116-128. DOI: https:// doi.org/10.1016/j.ins.2016.01.052

Ang, J. S. (1991). Small business uniqueness and the theory of financial management. Journal of Small Business Finance, $1,1-13$.

Arens, A., Elder, J., \& Beasley, M. (2007). Auditoría, un enfoque integral. México DF: Pearson, Prentice Hall.

Bacha, S. (2014) Determinants of debt cost financing of Tunisian companies: Bivariate analysis between 2000 and 2011. International Review of Management and Business Research, 3(2), 579-590.

Banco Central de la República Argentina (2018). Texto ordenado de las Normas sobre "Gestión Crediticia" al 19/01/2018. Consultado el 19/04/2018. Disponible en http://www.bcra.gob.ar/Pdfs/Texord/t-gescre.pdf

Bellovary, J., Giacomino, D., \& Akers, M. (2006). Weighting the public interest: Is the going concern opinion still relevant? The CPA Journal, 76(1), 16-21.

Berger, A., \& Udell, G. (2002). Small business credit availability and relationship lending: The importance of Bank Organizational Structure. Economic Journal, 112, 32-53. DOI: https://doi.org/10.1111/1468-0297.00682

Bessell, M., Anandarajan, A., \& Umar, A. (2003). Information content, audit reports and going-concern: an Australian study. Accounting and Finance, 43, 261-282. DOI: https://doi.org/10.1111/j.1467-629x.2003.00091.x

Boolaky, P., \& Quick, R. (2016). Bank directors' perceptions of expanded auditor's reports. International Journal of Auditing, 20, 158-174. DOI: https://doi.org/10.1111/ijau.12063

Briozzo, A., \& Vigier, H. (2009). A demand-side approach to SME's capital structure. Evidence from Argentina.Journal of Business and Entrepreneurship, 21, 30-56.

Briozzo, A., \& Vigier, H. (2014). The role of personal loans in the financing of SMEs. Academia Revista Latinoamericana de Administración, 27(2), 209-225. DOI: https://doi.org/10.1108/ARLA-10-2013-0167

Briozzo, A., Vigier, H., \& Martinez, L. (2016). Firm-level determinants of SME's financing decisions. Evidence from Argentina. Latin American Business Review, 17(3), 245-268.

Cassar, G. (2011). Discussion of the value of financial statement verification in debt financing: Evidence from private U.S. firms. Journal of Accounting Research, 49(2), 507-528.

Censo Nacional de la Población - CNP. (2010). Instituto Nacional de Estadísticas y Censos (INDEC).

Cha, M., Hwang, K. \& Yeo, Y. (2016). Relationship between audit opinion and credit rating: evidence from Korea. Journal of Applied Business Research, 32(2), 621-634. DOI: 10.19030/jabr.v32i2.9599

Chen, P., He, S., Ma, Z., \& Stice, D. (2016). The information role of audit opinions in debt contracting. Journal of Accounting and Economics, 61, 121-144. DOI: https://doi.org/10.1016/j.jacceco.2015.04.002

Citron, D., \& Taffler, R. (2001). Ethical behaviour in the UK audit profession: The case of the self-fulfilling prophecy under going-concern uncertainties. Journal of Business Ethics, 29(4), 353-363. DOI: https://doi.org/10.1023/ A: 1010752209148

Chittenden, F., Hall, G., \& Hutchinson, P. (1996). Small firm growth, access to capital markets and financial structure: Review of issues and an empirical investigation. Small Business Economics, 8, 59-67. DOI: https:// doi.org/10.1007/BF00391976

Church, B., Davis, S., \& McCracken, S. (2008). The auditor's reporting model: A literature overview and research synthesis. Accounting Horizons, 22(1), 69-90. DOI: https://doi.org/10.2308/acch.2008.22.1.69

DeAngelo, L. E. (1981). Auditor size and audit quality. Journal of Accounting and Economics, 3(3), 183-199.

Español, G., \& Subelet, C. (2014). Resolución Técnica N 37. Normas de Auditoría. Revisión, otros encargos de aseguramiento, certificación y servicios relacionados, 2a ed. Buenos Aires: Osmar D. Buyatti.

FACPCE - Federación Argentina de Consejos Profesionales de Ciencias Económicas. Resolución Técnica 16\#\#. Marco conceptual de las normas contables profesionales distintas a las referidas en la Resolución Técnica $N^{\circ} 26$. Buenos Aires: FACPCE. 
FACPCE - Federación Argentina de Consejos Profesionales de Ciencias Económicas (2013). Resolución Técnica 37 Normas de Auditoría, Revisión, Otros Encargos de Aseguramiento, Certificación y Servicios Relacionados.

FAFAE - Foro Argentino de Firmas de Auditores Externos (2014). Contabilidad, Auditoría y desarrollo económico. Consultado el 15/07/2017. Disponible en http://www.consejo.org.ar/noticias14/files/rolcontayaudit.pdf

Guiral, A., Ruiz, E., \& Choi, H. (2014). Audit report information content and the provision of non-audit services: evidence from Spanish lending decisions. Journal of International Accounting, Auditing and Taxation, 23(1), 44-57. DOI: https://doi.org/10.1016/j.intaccaudtax.2014.01.001

Guiral-Contreras, A., Gonzalo-Angulo, J., \& Rodgers W. (2007). Information content and recency effect of the audit report in loan rating decisions. Accounting and Finance, 47(2), 285-304. DOI: https://doi.org/10.1111/ j.1467-629X.2006.00208.x

Guiral, A., \& Ruiz-Barbadillo, E. (2011). Audit Report Information Content and Auditor Economic Independence in Credit Decisions: An experimental investigation. Consultado el 03/05/2018. Disponible en https://ssrn.com/ abstract $=1600643$

Gyau, E., Owusu F., \& Amaning N. (2016). The effect of audit report on investments and lending decisions in Ghana. European Journal of Accounting, Auditing and Finance Research, 4(4), 18-24.

Hernández S., R., Fernández C. C., \& Baptista L., P. (2010). Metodología de la Investigación, 5a ed. México DF: McGraw-Hill.

IASB (2010). The Conceptual Framework for Financial Reporting. Londres: IFRS Foundation.

Jensen, M. (1986). Agency costs of free cash flow, corporate finance and takeovers. American Economic Review Papers and Proceedings, 76(2), 323-329.

Jensen, M., \& Meckling, W. (1976), Theory of the firm: Managerial behavior, agency costs and ownership structure. Journal of Financial Economics, 3, 305-360.

Karjalainen, J. (2011). Audit quality and cost of debt capital for private firms: Evidence from Finland. International Journal of Auditing, 15, 88-108. DOI: https://doi.org/10.1111/j.1099-1123.2010.00424.x

Lai, K. (2009). Does audit quality matter more for firms with high investment opportunities? Journal of Accounting and Public Policy, 28(1), 33-50. DOI: https://doi.org/10.1016/j.jaccpubpol.2008.11.002

Lin, Z., Tang, Q., \& Xiao, J. (2003). An experimental study of users' responses to qualified audit reports in China. Journal of International Accounting, Auditing \& Taxation, 12, 1-22. DOI: https://doi.org/10.1016/ S1061-9518(03)00005-3

Mansi, S., Maxwell, W., \& Miller, P. (2004). Does auditor quality and tenure matter to investors? Evidence from the Bond Market. Journal of Accounting Research, 42(4), 755-793. DOI: https://doi.org/10.1111/ j.1475-679X.2004.00156.x

Minnis, M. (2011). The value of financial statement verification in debt financing: Evidence from private US firms. Journal of Accounting Research, 49(2), 457-506.

Niemi, L., \& Sundgren, A. (2012). Are modified audit opinions related to the availability of credit? Evidence from Finnish SMEs. European Accounting Review, 21(4), 767-796. DOI: https:// doi.org/10.1080/09638180.2012.671465

Pucheta, M. C., \& Vico, A. (2008). ¿Reaccionan los analistas de riesgos comerciales de las empresas españolas ante los informes de auditoría calificados?: Un estudio empírico. Revista de Contabilidad, 11(2), 67-92.

Ranninger, B. (2013). Changes to the Auditor's Report and the effects for the bank lenders in the Austrian financial market. Master's Thesis. Dublin Business School.

Sormunen, N. (2014). Bank officers' perceptions and uses of qualified audit reports. Qualitative Research in Accounting \& Management, 11(3), 215-237. DOI: https://doi.org/10.1108/QRAM-04-2012-0013

Van Caneghem, T., \& Van Campenhout, G. (2012). Quantity and quality of information and SME financial structure. Small Business Economics, 39(2), 341-358. DOI: https://doi.org/10.1007/s11187-010-9306-3 
Van Tendeloo, B., \& Vanstraelen, A. (2008). Earnings management and audit quality in Europe: Evidence from the private client segment market. European Accounting Review, 17(3), 447-469. DOI: https:// doi.org/10.1080/09638180802016684

Vazquez, R., Bongianino de Salgado, C., Sosisky, L., \& Albano, H. (2006). Modelización del esquema de investigación en contabilidad. En Scarano et al. Metodología de la Investigación Contable. Buenos Aires: Universidad de Buenos Aires.

Weiss, R. S. (1994). Learning from strangers: the art and method of qualitative interview studies. Nueva York: The Free Press.

\section{Notas}

* Artículo de investigación científica.

[1] El término oblea que utilizó el Entrevistado 13, se refiere a la estampilla colocada en los estados financieros por el Consejo de Profesionales en Ciencias Económicas cuando se certifica la firma del profesional que ha actuado como auditor o certificante.

\section{Licencia Creative Commons CC BY 4.0}

